\title{
Cooperation Mechanisms To Achieve Eu Renewable Targets
}

\author{
Klinge Jacobsen, Henrik; Pade, Lise-Lotte; Schröder, Sascha Thorsten; Kitzing, Lena
}

Published in:

Renewable Energy

Link to article, DOI:

10.1016/j.renene.2013.09.035

Publication date:

2014

Document Version

Peer reviewed version

Link back to DTU Orbit

Citation (APA):

Klinge Jacobsen, H., Pade, L-L., Schröder, S. T., \& Kitzing, L. (2014). Cooperation Mechanisms To Achieve Eu Renewable Targets. Renewable Energy, 63, 345-352. https://doi.org/10.1016/j.renene.2013.09.035

\section{General rights}

Copyright and moral rights for the publications made accessible in the public portal are retained by the authors and/or other copyright owners and it is a condition of accessing publications that users recognise and abide by the legal requirements associated with these rights.

- Users may download and print one copy of any publication from the public portal for the purpose of private study or research.

- You may not further distribute the material or use it for any profit-making activity or commercial gain

- You may freely distribute the URL identifying the publication in the public portal

If you believe that this document breaches copyright please contact us providing details, and we will remove access to the work immediately and investigate your claim. 


\title{
COOPERATION MECHANISMS TO ACHIEVE EU RENEWABLE TARGETS
}

Henrik Klinge Jacobsen ${ }^{a}$ Lise Lotte Pade ${ }^{a}$; Sascha Thorsten Schröder ${ }^{a}$; Lena Kitzing ${ }^{a}$

\begin{abstract}
DTU Management Engineering, Technical University of Denmark,
\end{abstract}
Systems Analysis Division,P.O. Box 49, DK-4000 Roskilde, Denmark

\section{Postprint \\ Renewable Energy 63, March 2014, pp. 345-352 \\ 10.1016/j.renene.2013.09.035}

\begin{abstract}
There are considerable benefits from cooperating among member states on meeting the 2020 renewable energy sources (RES) targets. Today countries are supporting investments in renewable energy by many different types of support schemes and with different levels of support. The EU has opened for cooperation mechanisms such as joint support schemes for promoting renewable energy to meet the 2020 targets. The potential coordination benefits, with more efficient localisation and composition of renewable investment, can be achieved by creating new areas/sub-segments of renewable technologies where support costs are shared and credits are transferred between countries.

Countries that are not coordinating support for renewable energy might induce inefficient investment in new capacity that would have been more beneficial elsewhere and still have provided the same contribution to meeting the 2020 RES targets. Furthermore, countries might find themselves competing for investment in a market with limited capital available. In both cases, the cost-efficiency of the renewable support policies is reduced compared to a coordinated solution.

Barriers for joint support such as network regulation regarding connection of new capacity to the electricity grid and cost sharing rules for electricity transmission expansion are examined and examples given. The influence of additional renewable capacity on domestic/regional power market prices can be a barrier. The market will be influenced by for example an expansion of the wind capacity resulting in lower prices, which will affect existing conventional producers. This development will be opposed by conventional producers, whereas consumers will support such a strategy.

A major barrier is the timing of RES targets and the uncertainty regarding future targets. We illustrate the importance of different assumptions on future targets and the implied value of RES credits. The effect on the credit price for 2020 is presented in an exemplary case study of 200MW wind capacity.
\end{abstract}




\section{Keywords: RES target, cooperation mechanisms, policy coordination, renewables, European energy policy}

\section{Introduction}

The European Union (EU) has defined an overall target for renewable energy of 20\% in 2020. The required total addition of renewable energy for the EU has been distributed among the Member States (MS) and translated into national targets for renewable energy taking into account selected parameters. The national targets are mainly based on an equal increase from the respective shares in 2005. The income level is one additional parameter: a slightly higher burden is put on wealthier countries. However, no consideration has been made to integrating cost efficient implementation into the allocation of national targets. Tolon-Becerra et. al. [1] examine alternative distribution weights among EU member state targets and illustrate that the targets chosen by the EU could be substantially different for some countries if more or less weight is put on initial energy consumption per capita or income levels/GDP. While the different weights in the analysis of Tolon-Becerra et. al. [1] do not intend to minimise costs of meeting the aggregate $20 \%$ EU target in 2020, it shows that the resulting target allocation can vary significantly, depending on the parameters chosen. The cost differences across Europe of implementing renewable investment have not been directly included in setting the targets. Since these cost differences can be significant for some technologies and regions, there exist potential benefits if some of the investment needed to comply with the overall European target could be re-allocated from countries with high cost renewable options to countries with lower cost options. This will lead to overall reduced compliance cost in Europe. These potential benefits could be realised if countries are allowed to implement their targets jointly. An overview of quantitative studies indicating the possible gains due to cooperation is given in [2]. With the Directive 2009/28/EC [3], EU legislation has opened for cooperation mechanisms to benefit from efficiency gains. They comprise joint support schemes, joint projects and statistical transfers as support for promoting renewable energy to meet the 2020 targets. The details for these mechanisms have not been laid out yet. A communication from the commission in 2013 [4] strengthens the call for more initiatives on cooperation as the target achievement in 2020 has become uncertain as member states have taken insufficient actions on reducing barriers and reductions in national incentives/support for renewables has reduced medium term prospect for meeting trajectory targets.

Despite the national characteristics of support mechanism choice, [5] argue that national schemes are converging to a certain extent, possibly facilitating multilateral agreements on joint support. The purpose of this article is to analyse the barriers for cooperation mechanisms and possible policy solutions. Furthermore, the article investigates the importance of future RES targets for cooperation mechanisms. It takes thus a more general approach than [6], who illustrate the possible combination of support schemes and cooperation mechanisms specifically for offshore wind energy. The least complicated mechanism is the statistical transfer, an ex-post transfer of 
virtual RES certificates that can be used for target compliance. This mechanism depends directly on governmental involvement and can also be associated with the other mechanisms at the final stage of transferring the achieved RES certificates from one country to another. As Klessmann et al. (2010) [7] argue, statistical transfers are not expected to induce significant amounts of additional RES development. They argue further that statistical transfers will most likely be used as an ex-post allocation mechanism for excess certificates rather than as a mechanism to strategically increase the efficiency in the distribution of RES development. Due to the incentive structure behind this mechanism, it is expected that only very limited 'statistical transfervolumes' will be available to MS for complying with their target in 2020 [4]. The reason is that, if this mechanism should be used as strategic instrument rather than as an ad-hoc means of 'filling the gaps', MS would have to guarantee the delivery of RES certificates under a statistical transfer several years prior to 2020 so that the receiving MS can avoid the development of own RES production. However, many MS (especially those using feed-in tariffs or other non quantity-driven support systems) will not be able to guarantee delivery long before 2020, as they will be uncertain in regards to their own target compliance. Therefore, sharing of compliance risk would be a critical issue in agreements on statistical transfers ex ante. A case study from an Austrian perspective on this issue is provided in [8], finding that joint support could minimise the EU-wide support sum by several billion Euro. For the Austrian case, the authors argue that the country could strive to over achieve its RES targets as a hedge against variations in other factors and, if not required, sell excess generation under a statistical transfer.

This paper is structured as follows: We first provide an overview of the possible sources of benefits from cooperating on meeting renewable targets in section 2. In section 3 follows an investigation of the barriers for cooperation mechanisms. Finally, section 4 examines the importance of post 2020 RES targets for cooperation design and credit transfer pricing. Section 5 presents the conclusions.

\section{Potential benefits of cooperation}

Countries that are designing their support schemes for renewable energy independently might induce inefficient investment in new capacity that would have been more beneficial abroad and still provide the same contribution to meeting the European 2020 RES targets. Additionally, the countries might also find themselves competing for investment in a market with limited capital available. In both cases, the cost-efficiency of the renewable support policies will be reduced relative to a coordinated solution.

The fact that a country actually has difficulties meeting their own 2020 RES target, for example due to limited resources or adverse market conditions, is not the determining factor for whether a country will benefit from cooperation. Assuming that the costs of installing the marginal RES unit in one country is less than the costs of installing the marginal RES unit in another country, the country with the highest marginal costs of RES will benefit from installing its RES in the first country. Furthermore, as the countries will enter an agreement sharing the total savings, the 
country with the lowest marginal RES costs also benefit from cooperation. A country-to-country trading approach has been found superior to a trading system between companies [9].

In this paper, we look mainly on a situation where there are considerable benefits caused by large differences in RES costs and differences in other parameters such as power prices that can facilitate secondary benefits as well. The benefits of cooperation can be grouped into two categories:

1. Primary benefits: reduced target compliance costs

2. Secondary benefits: e.g. reduced cost in electricity supply and faster RE technological progress

\subsection{Primary benefits}

Cooperation and coordination across countries can contribute to a more efficient expansion of renewable generation in Europe and can therefore reduce the costs of compliance with the 2020 renewable targets. Often, the main potentials for addition of renewable energy are located in border areas between markets with different support schemes and different rules for market access, market integration (incl. balancing responsibility) and development of transmission capacity. It can be expected that benefits can be harnessed especially in these areas. The main cost reduction can be expected from direct RES costs, but the value of the potential generation depends heavily on the power market structure and generating capacity mix in general.

The larger the difference between marginal costs of RES expansion between two countries, the larger the benefits of jointly meeting the targets will be since the country with the very high costs of RES expansion will face substantially lower costs exploiting the opportunity to install the RES in another country. The cost reduction will not be equally shared between the two countries in the first place. This stresses the need for the participating countries to develop a mechanism securing proper sharing of the cooperation benefits.

\subsection{Secondary benefits}

It is quite important that the primary benefits, given by reduced costs of compliance with 2020 renewable targets, are not achieved at the expense of secondary objectives of the national RES policies. The secondary group of benefits of cooperation accounts for the less measurable benefits as well as other secondary policy objectives. Among these count:

- Power generation efficiency

- Employment effects

- Security of supply

- Investor risk

- Political risk 


\section{Power generation efficiency}

Increased cooperation could reduce power generation costs by allocating more renewable investments to countries where they replace existing inefficient power capacity. This is for example the case where additional power generation capacity is actually required to enable scrapping of very old capacity, as compared to countries where additional renewable generation will replace relatively new and efficient conventional generation. As the short term marginal costs of electricity production from RES are expected to be less than the short term marginal cost of conventional (fossil) technologies, price reductions in electricity supply are expected. However, this is not an efficiency increase since it is the long term costs that exhibit the economic efficiency. Cooperation projects that involve expanding the interconnection capacities, for example to bring offshore wind power a-shore in a high price area would certainly also improve the generation allocation efficiency. These efficiency benefits will not necessarily be evenly distributed and the price effects most likely will be different in cooperating countries. Nevertheless, the efficiency improvement could provide an important net benefit that could accrue to the country that only has limited direct benefits from the reduction of RES target compliance costs.

\section{Employment effects}

Investment in renewable deployment creates temporary employment in the construction phase, and permanent employment in operation and maintenance [10-15]. The short term employment benefit is often assumed to affect more remote areas with weak employment opportunities [14] to a higher degree than conventional power plant investments. Permanent jobs are also for some renewable technologies (biomass) seen as exceeding the number of jobs that they replace in the conventional generation [10].

Security of supply

Another benefit from cooperation across countries is increased security of supply. This is especially the case if cooperation involves increased interconnection capacity. Interconnection will also reduce the reserve capacity requirement and thereby costs of securing supply. Additionally, possible positive effects from harmonising connection, planning, and support administrative procedures will lead to faster implementation of best practices and thus improved security of supply.

Investor risk

One of the barriers for investors in terms of investing in renewable energy is the regulatory risk. Facing a new technology investors being uncertain of the future support policy will choose to invest their money in other markets. However, joint support schemes across countries targeting the 2020 RES targets will imply a larger degree of certainty as a change in the support scheme would be equal to a breach of international contracts and is therefore not expected. 


\section{Political risk}

Finally, reduced political risk represents a secondary benefit of cooperation. The risk of not complying with the 2020 RES targets for the country initially being in lack of renewable capacity will be strongly reduced if not eliminated.

Since the secondary benefits as a point of departure is rather difficult to measure monetarily in contrast to the primary benefits (see above), the risk that the primary benefits are achieved at the expense of some secondary benefits must be minimised.

The potential secondary coordination benefits with more efficient localisation and composition of renewable investment can be partly achieved by creating new areas and sub-segments of renewable technologies where support costs and credits are shared. Such a solution enables the parties to avoid loss of secondary benefits that are linked to their own national support policies for all the RES not included in the new cooperation.

\section{Barriers for cooperation}

The overall prerequisite is that MS will only agree on a cooperation mechanism if they both benefit from it. A mutually beneficial situation can be achieved if the overall benefits are greater than the overall cost and if the costs and benefits are allocated between the MS in an adequate way.

Klessmann (2009) [15] describes the different elements of costs and benefits for each MS under a cooperation mechanism: The primary costs are the support for the produced RES electricity (i.e. feed-in premiums). The primary benefit is the contribution to RES target compliance. As described in the previous section, there are a number of secondary cost and benefits that require additional adjustments to allocation agreements. Difficulties in quantifying these secondary costs and benefits may lead to certain barriers for the implementation of cooperation mechanisms. In [16], an overview of all the possible barriers for cooperation is provided and the most severe identified. In some situations the secondary benefits will be entirely shifted between MS in cooperation and this could be effectively hindering the cooperation.

Especially local benefits (jobs, security of supply, innovation, export options) are often mentioned as a significant element by political decision makers. Therefore, they constitute a barrier if they will be negatively affected in one of the countries engaging in cooperation. Additionally, the compensation for such losses are very hard to translate into a quantifiable price premium on the RES-certificate transfer price. The value of these effects is expected to be relatively limited compared to the primary effects, and is therefore not included in this paper.

Another relevant barrier is the one arising as a result of different policy objectives of the support schemes. Objectives may be to 1) maintain support for diversified technologies in order to increase political acceptance or to 2) target the support in order to develop specific RES technologies and industries. Furthermore, different levels of support as well as the usage of different support mechanisms may appear to constitute barriers to cooperation. We therefore 
suggest that, for example, feed-in tariffs for the cooperation can be set at levels that diverge from the rest of the national renewable market without distorting the intended composition in the national market.

Barriers also include the influence on domestic/regional power market prices. One market will be influenced by for example wind expansion with lower prices that will reduce earnings for existing conventional producers. Such a development will be opposed by existing producers whereas consumers, who will benefit from it, will support such a strategy. However, the investment will be influenced by decisions of producers as well as the possibility of increasing connection to other markets with higher market prices, which could reduce the effect of the increased RES capacity on the market price.

Finally, there are several other issues that can constitute possible barriers, such as how to structure the agreements legally, how to allocate cost of joint support into the PSO (Public Service Obligations) payments for consumers, etc. These issues are not perceived as major barriers and are expected to be fairly easy to overcome [16].

Table 1 Cooperation mechanism characteristics, barriers and solutions

\begin{tabular}{|c|c|c|c|c|c|}
\hline $\begin{array}{l}\text { Cooperation } \\
\text { mechanism }\end{array}$ & $\begin{array}{l}\text { Primary cost } \\
\text { saving } \\
\text { potential }\end{array}$ & $\begin{array}{l}\text { Secondary } \\
\text { benefits involved }\end{array}$ & $\begin{array}{l}\text { Barriers for } \\
\text { implementation }\end{array}$ & $\begin{array}{l}\text { Solution for } \\
\text { barriers }\end{array}$ & $\begin{array}{l}\text { Possible time } \\
\text { horizon for } \\
\text { implementation }\end{array}$ \\
\hline $\begin{array}{l}\text { Harmonised } \\
\text { joint support } \\
\text { scheme }\end{array}$ & $\begin{array}{l}\text { Large } \\
\text { A full } \\
\text { harmonised } \\
\text { system without } \\
\text { technology } \\
\text { differentiation of } \\
\text { support yields the } \\
\text { highest efficiency } \\
\text { gain }\end{array}$ & $\begin{array}{l}\text { Larger markets, } \\
\text { More competition, } \\
\text { National secondary } \\
\text { support objectives } \\
\text { difficult to maintain } \\
\text { Harmonisation in } \\
\text { other market } \\
\text { conditions and } \\
\text { increased power } \\
\text { market integration }\end{array}$ & $\begin{array}{l}\text { Considerable } \\
\text { time delays in } \\
\text { legislation, } \\
\text { Difficult to } \\
\text { compensate directly } \\
\text { the losers, } \\
\text { National control of } \\
\text { support policy } \\
\text { reduced }\end{array}$ & $\begin{array}{l}\text { Compensation } \\
\text { mechanisms and } \\
\text { cooperation on } \\
\text { reaching secondary } \\
\text { objectives (infant } \\
\text { industries, employment } \\
\text { and diversification of } \\
\text { technologies), } \\
\text { Allocation of net } \\
\text { benefits to losers }\end{array}$ & $\begin{array}{l}\text { Complicated and } \\
\text { requires national } \\
\text { legislation delays } \\
\text { Long term option }\end{array}$ \\
\hline $\begin{array}{l}\text { Local/regional } \\
\text { joint support } \\
\text { scheme }\end{array}$ & $\begin{array}{l}\text { Medium level } \\
\text { Advantage for } \\
\text { countries with } \\
\text { shared/bordering } \\
\text { resources }\end{array}$ & $\begin{array}{l}\text { Maintained national } \\
\text { support for not } \\
\text { covered areas and } \\
\text { technologies expand } \\
\text { excess resources }\end{array}$ & $\begin{array}{l}\text { Opposition to } \\
\text { favoring investment } \\
\text { in one area opposed } \\
\text { to those areas } \\
\text { covered by national } \\
\text { scheme }\end{array}$ & $\begin{array}{l}\text { Replicate one system } \\
\text { from one of the } \\
\text { cooperating countries - } \\
\text { limited legislative } \\
\text { delay }\end{array}$ & $\begin{array}{l}\text { Medium term time } \\
\text { scale }\end{array}$ \\
\hline $\begin{array}{l}\text { Joint projects } \\
\text { cooperation }\end{array}$ & $\begin{array}{l}\text { Small to medium } \\
\text { advantage for few } \\
\text { large projects }\end{array}$ & $\begin{array}{l}\text { Maintain own } \\
\text { support systems and } \\
\text { secondary objectives }\end{array}$ & $\begin{array}{l}\text { Transaction costs, } \\
\text { Lack of } \\
\text { transparency, } \\
\text { Legal requirements } \\
\text { because of lack of } \\
\text { legislation }\end{array}$ & $\begin{array}{l}\text { Target technologies } \\
\text { with large project size }\end{array}$ & $\begin{array}{l}\text { Short term time } \\
\text { scale }\end{array}$ \\
\hline $\begin{array}{l}\text { Joint projects } \\
\text { support } \\
\text { framework }\end{array}$ & Medium & $\begin{array}{l}\text { Maintain own } \\
\text { support systems and } \\
\text { secondary objectives }\end{array}$ & $\begin{array}{l}\text { Transaction costs } \\
\text { lower than for } \\
\text { single project }\end{array}$ & $\begin{array}{l}\text { Identify } \\
\text { technologies/areas } \\
\text { where standardisation } \\
\text { easy and many small } \\
\text { projects works better } \\
\text { than a few large }\end{array}$ & $\begin{array}{l}\text { Medium term time } \\
\text { scale }\end{array}$ \\
\hline
\end{tabular}


Table 1 provides an overview of the main characteristics of the cooperation mechanisms, the barriers and possible solutions. The following sections explain single barriers related to different support schemes and power market effects in more detail.

\subsection{Barriers as a consequence of different RES support systems and policy objectives}

There are considerable barriers related to differences in support systems between countries, but just as important is the barrier from a difference in the level (cost) of support. Differences in support systems cover feed-in tariffs, feed-in premiums, green certificates or tendering auctions as well as differences in technology coverage with technology banding or technology-specific support level.

Cooperation between countries with different support systems can be initiated in two ways of which one is moving in the direction of harmonising the two support systems/schemes. The other option is to progress with different systems but initiate cooperation based on cooperation projects or just using the statistical transfer to exploit imbalances realised ex post in 2020. The first case will require very substantial changes to legislation and institutional arrangements where adjustments costs and time lags are considerable barriers. In the second case with project-based cooperation, these costs and time lags are less, but the transaction costs and administrative burdens in order to have sufficient volume in projects can be substantial unless standardisation is widely possible. Statistical transfers have the lowest barriers, but they cannot ensure additional RES in time or the relocation of RES development.

As countries often apply different support schemes targeting different technologies [17], barriers will arise when determining which support scheme to apply in the cooperation, independent on whether the two countries agree on going in the direction of harmonising their support systems or they agree on project-based cooperation. In the following, we examine barriers that may arise as a consequence of different support systems in the cooperating countries. In [16] several different combinations have been analysed, but here we include only two of the characteristic combinations.

\section{- Barriers for combining feed-in and green certificate support schemes}

The two support schemes offer different properties with regard to the volumes realised and the support costs. Feed-in does not control the volume and could generate both excess and deficit results relative to 2020 RES targets. Green certificate schemes require a broader range of conditions fulfilled to work well, of which the liquidity and transparency of the market is most difficult to satisfy. Combing the two is possible with feed-in for some technologies, where the countries prioritise their secondary objectives such as PV industry development and a common certificate system for other technologies. The main barrier is that the feed-in easily offer technology specific support level and the certificates would work best with competition between 
technologies. One option to combine the two schemes is to introduce technology banding in a common certificate scheme and another option is to combine a certificate scheme with feed-in tariffs or premiums for a few technologies or installation sizes. In either case, there is a trade-off between the efficiency of the scheme to promote the cheapest options and the degree to which the combined scheme is supporting diversified technologies. Barriers arise as a feed-in tariff supports the purpose of developing infant domestic industries, conflicting with the idea of implementing RES development where it is cheapest, which certificates would support. If technology banding (technology specific support) motivated by concerns such as security of supply, diversification of power technologies etc. is desired, a feed in tariff is often the preferred instrument. Feed-in tariffs and premiums generally offer less risk in the support revenue to investors, whereas the certificate revenue is heavily dependent on if there is a political commitment to increase the renewable obligations over time. Smaller investors would normally favour the feed-in to the certificate scheme if the intended level of support is in the same range.

\section{- Barriers for combining feed-in and tendering schemes}

Feed-in schemes work well with both smaller and larger projects, but are inflexible in providing the market incentive to increase or cut back on RES deployment speed. Tendering works well with larger projects that require interaction with governmental/TSO planning of infrastructure and localisation of investment etc. Feed-in and tendering is often combined with a fixed support

at the time of settling with the tender winners, but new tenders are not bound with any level of feed-in tariff. The actual expansion of renewables can thus be controlled contrary to a feed-in. In cases where the tenders are for additional high-cost RES options and can be used for cooperation and RES certificate exchange, the combination of tenders and a general feed-in could work.

\subsection{Barriers related to differences in support levels}

Differences in support levels create barriers as they are expressing the different willingness of society to pay for renewable expansion. Harmonising different support levels necessarily means that the renewable investment opportunities in the country of high support level are reduced (see Box 1). Renewable industry, green development supporters and renewable investors would all oppose the reduction of support levels even though it is the cooperation benefit that reduce costs and therefore enable more ambitious RES targets in the future. Likewise the country with low support would have important opposition against the increase in support cost for their RES development especially if the burden is directly levied over consumers. 
For example, Germany and Spain could decide to cooperate on a joint support scheme for new photovoltaic (PV) installations. The two support schemes are currently rather similar, featuring a differentiated feed-in tariff. Spain recently introduced a capacity cap, limiting the support of new PV installations, because they feared a too high increase of their overall RES support cost. At the same time, there is a significant build-out of PV in Germany to a much higher RES support cost. Assuming a joint support system, where Germany and Spain would have one common market for PV at an adequate common support level, the build-out of PV would move from Germany to Spain (due to the much better solar radiation levels). The overall support cost would be reduced by the difference of the required support cost in Germany to the required support cost in Spain. Germany and Spain would then share the RES certificates and the support cost. However, finding the right cost allocation would be a difficult negotiation. Germany would have a significant reduction in support cost (per generated unit of renewable energy), but would also lose local benefits. Spain would need to be compensated for bearing all physical and market integration issues, but would have all local benefits including the innovation and industry benefits, which currently seems to be a significant factor in Germany's PV support considerations.

\subsection{Barriers related to targets over time}

Uncertainty about more ambitious post-2020 targets can be another hindrance to attaining 2020 targets jointly. If cheap resources are predominantly in one country (A), a common support scheme may 'sell' these resources to the neighbour B at a low price. At a later point in time, higher RES targets cannot be obtained by A alone because low-price locations are blocked. Thus, choosing an international support solution may impact the possible future choices negatively from a unilateral point of view. 


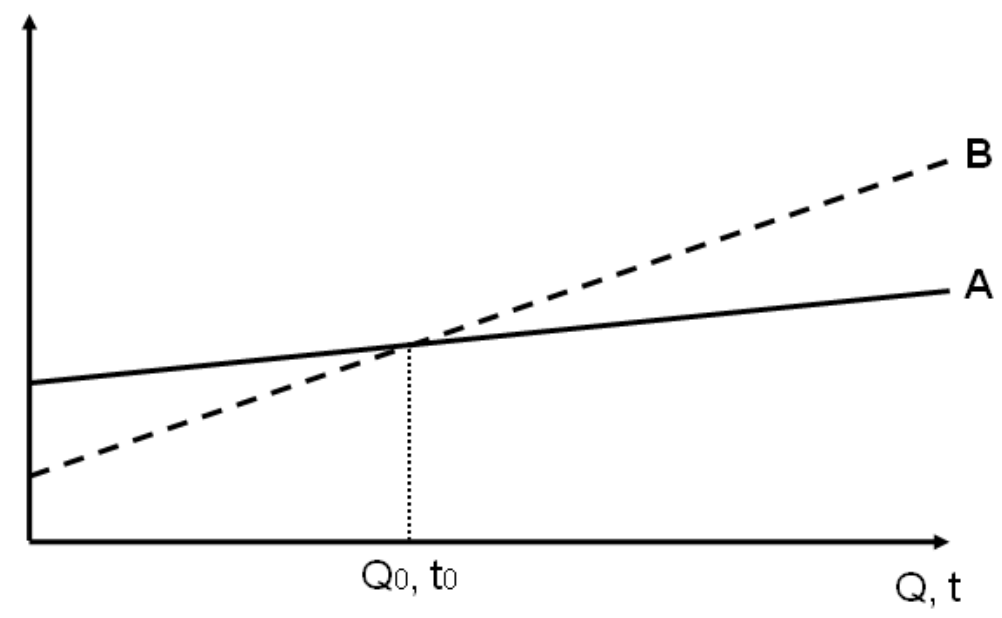

Figure 1: Marginal costs of RES extension in countries A and B over time

The picture could be different if the marginal costs of RES extension in the two countries intersect, as illustrated in Figure 1. The figure displays the marginal costs of RES extension of two countries A and B over time $t$ and the RES amount Q. Until the intersection at Qo/to, RES extension can be achieved at lower cost in B, and vice versa. In such a constellation, a cooperation could be politically more acceptable for both parties because A receives access to low-cost resources in the short run while B secures access to lower-cost resources in the long run (beyond $\mathrm{Q}_{0}$ ). The joint support scheme could be a quota mechanism, a feed-in tariff scheme or a price premium scheme. As for all support schemes, basic features such as geographical and technological scope and a time horizon for its applicability need to be defined. A tendering scheme could also be suitable for a number of large-scale technologies such as offshore wind power. If support is granted over a certain time horizon, e.g. 15 years, this extends beyond the 2020 targets. Support to units in a neighbouring country may then have to be provided on an annual basis, although the support does only contribute to fulfilling RES for 2020.

\subsection{Barriers associated with power market regulation, composition of technologies and price levels}

This subsection addresses the following topics:

- Difference in network regulation (incentive regulation) approach

- Difference in power market design/functioning

- Difference in power market price and price volatility

- Difference in generation mix and mix of RES technologies

\section{- Barriers related to network regulation}

Network regulation varies a great deal between member states from rate of return to incentive based price and revenue caps. The details in incentive regulation include numerous differences 
and the enforcement of regulation is not always effective. Network regulation has impacts on the incentives to facilitate efficient connection of new technologies and network reinforcements [18]. If national regulation allows networks to include reinforcement investments caused by renewable generation in their capital base and thereby their revenue cap, this cost will be borne by the network customers. In the case of cooperation, the country providing the RES credits will require the receiving country to compensate also for this cost, but the transfer to network customers in the receiving country seem very difficult to realise. Box 2 gives a short example how the network connection could be used as a trade-off option.

\section{Box 2 Example: Connection costs as a barrier and possible solutions}

The sharing of connection costs seems to offer benefits from a practical point of view: if a joint support scheme refers to an offshore area and is connected to several countries, the involved TSOs need to agree on a division of investment costs. This may be done proportionally to expected national benefits and could also comprise further effects arising from a joint support scheme.

\section{- Barriers related to power market characteristics}

Power markets differ even though they are in many cases coupled and therefore prices to some extent are correlated. Differences in market concentration and technology composition create some barriers. The mix of technologies in power generation can be more or less flexible to adjust to short term changes in renewable generation. This can constitute an important barrier in a country if the inflexibility of the existing generation capacity is combined with adding more fluctuating renewable generation than necessary for national purposes.

\section{- Barriers related to power price effects}

Power price level and volatility differ and create additional barriers. Price levels in some countries will not be affected considerably by increasing or decreasing the renewable expansion, whereas a neutral price zone between two countries is subject to a comparatively low-price profile [19]. However, countries where renewable expansion potentials are abundant and cheap could experience considerable changes in power prices and corresponding deterioration in profitability of existing conventional and renewable capacity. It is a difficult task to compensate the firms/producers that lose with the gains that consumers experience in terms of lower prices. At the same time, the country facing the reduced prices will probably have to look for alternative ways to provide incentives for future investment in conventional capacity. Furthermore, there is a risk of increasing curtailment of renewable generators both in the short run and permanently by expanding fluctuating renewable at a fast pace. If curtailment is necessary, the issue of compensation to generators has to be agreed upon. [20] suggest that this should be with respect to primary dispatch: if this has been granted historically, compensation needs to follow, whereas the curtailment risk may stay with generators in a more liberalised market environment. 


\section{Cooperation with uncertain future RES targets}

One of the important barriers for cooperation lies in the uncertainty regarding the post 2020 targets for RES shares. The uncertainty influences the value of the possible RES credits from generation after 2020. Expecting tighter (higher) targets after 2020 will make excess countries reluctant to sell their relatively cheap RES options off. Countries in deficit considering buying credits will be reluctant to support foreign long term investments in RES without certainty that the generation credits after 2020 have any value. [21] also stress the importance of post 2020 targets and that cooperation and collaboration initiatives intended for that period will enhance also the prospects for achieving the 2020 targets.

Table 2 illustrates an exemplary cooperation setting for two countries A and B with differences in RES technology costs (column 2), power market price (column 3) and necessary support cost on top of the expected power prices in each country (column 4). The example demonstrate that the issue of uncertain future RES targets has important implications for the cooperation attractiveness where one country is partly or fully financing the necessary support for renewable projects in another country. The uncertainty about the future target is illustrated by varying the value (column 6) that country $A$ in which the development takes place assigns to credits after 2020.

The examples show the effect on the RES credits transfer price based on the value per generated unit in 2020. The assumptions underlying the calculations in Table 2 are: a technology lifetime of 15 years, annual generation 4100 full load hours from 2020, no discounting, constant real prices and support levels. The most crucial assumptions are the RES technology costs in column 2 and the expected value of future credits in column 6. For all levels of expected credit value, the calculations are carried out with and without a physical transfer of the generated electricity to the other market. The cost of interconnection capacity is not included in calculations. 
Table 2 Examples of RES credits prices with permanent or single year transfer, $200 \mathrm{MW}$ offshore wind

\begin{tabular}{|c|c|c|c|c|c|c|c|}
\hline 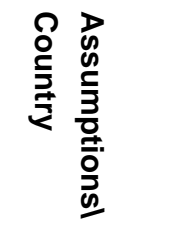 & 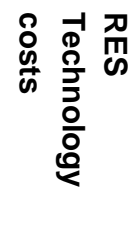 & 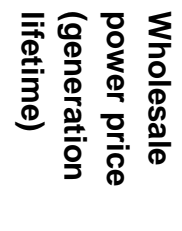 & 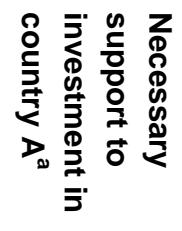 & 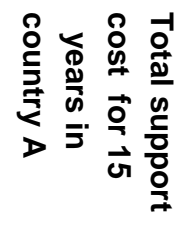 & 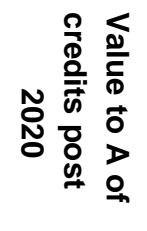 & 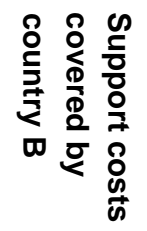 & 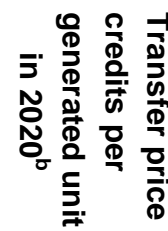 \\
\hline & $c € / k W h$ & $€ / M W h$ & $c € / k W h$ & Mill. $€$ & $c \in / k W h$ & Mill. $€$ & $c \in / k W h$ \\
\hline Country A & 12 & 40 & 8.0 & 984 & 0 & 984 & 120 \\
\hline Country B & 15 & 63 & 5.7 & 701 & 0 & 701 & 85 \\
\hline Country A & 12 & 40 & 8.0 & 984 & 2 & 754 & 92 \\
\hline Country B & 15 & 63 & 5.7 & 701 & 2 & 472 & 58 \\
\hline Country A & 12 & 40 & 8.0 & 984 & 4 & 525 & 64 \\
\hline Country B & 15 & 63 & 5.7 & 701 & 4 & 242 & 30 \\
\hline Country A & 12 & 40 & 8.0 & 984 & 6 & 295 & 36 \\
\hline Country B & 15 & 63 & 5.7 & 701 & 6 & 12 & 2 \\
\hline Country A & 14 & 40 & 10.0 & 1230 & 4 & 771 & 94 \\
\hline Country B & 15 & 63 & 7.7 & 947 & 4 & 488 & 60 \\
\hline
\end{tabular}

a: for the entire lifetime of the technology. With and without physical transfer (in italic)

${ }^{b}$ : assuming the support for the entire lifetime of the technology is paid in one single year, 2020

The last column is expressing the total lifetime support payments financed by country B per generated unit in one single year, namely 2020 . These are in most cases much higher than the necessary support costs per generation unit for the entire lifetime as illustrated in column 4 . If the support financed by country B covers the entire necessary support because country A assigns no value to future credits, this corresponds to country B buying all the credits at the price of $5.7 \mathrm{c} € / \mathrm{kWh}$ as in row 3. Such a situation can be expected for many bilateral cooperation possibilities in the EU. For most countries, the value of future RES credits will be rather low, but some countries might expect much higher RES targets for the future or they might have national targets that exceed the 2020 target set by the EU directive. This is for example the case for Denmark that has set higher targets for renewable shares post 2020.

As such, the basic cost savings from cooperation are found as the difference between RES generation costs in country A and country B. This is the cost differential in column 2 which is $3 \mathrm{c} € / \mathrm{kWh}$, except the alternative in the last two rows with only a $1 \mathrm{c} € / \mathrm{kWh}$ cost difference. Adding interconnection capacity between the two countries increase the gross benefit (italic figures) but it is not a result of the cooperation project and could have been achieved without the RES project. If there is much larger RES expansion than in the present 200MW example, there might be a downward effect on market prices in country A. This would increase the price differential and make the addition of interconnection capacity more economically attractive. 
In reality, the transfer price will be a result of a negotiation process and the example of 29.5 $\mathrm{c} € / \mathrm{kWh}$ (see Box 3 ) is a minimum price as the price has to be higher if country A should have a net benefit from the cooperation.

Box 3 Transfer price for 2020 credits including physical transfer, row 7

Calculation of the transfer price for 2020 credits with physical transfer as in row 7 can be exemplified by first calculating the necessary support (column 4):

$($ Technology cost in A $(12 \mathrm{c} € / \mathrm{kWh})$ - market price in B $(6.3 \mathrm{c} € / \mathrm{kWh})) * 4100$ hours/year* $200 \mathrm{MW} * 1000 \mathrm{kWh} / \mathrm{MWh} * 15$ years $=701.1$ mill. $€$.

Of this support, A will be willing to contribute up to the expected value of $4 \mathrm{c} € / \mathrm{kWh}$ for the remaining 14 years of generation: $200 \mathrm{MW} * 1000 \mathrm{kWh} / \mathrm{MWh} * 14$ years $* 4 \mathrm{c} € / \mathrm{kWh}=459.2$ mill. $€$.

Then B will have to pay 701.1 mill. $€-459.2$ mill. $€=242$ mill. $€$ for the RES generation credits in 2020 . This corresponds to $242 \mathrm{mill} . € /(200 \mathrm{MW} * 1000 \mathrm{kWh} / \mathrm{MWh} * 4100 \mathrm{~h})=29.5$ $\mathrm{c} € / \mathrm{kWh}$.

The last two rows in the table illustrate a situation where there is only a minor difference between the technology costs in countries A and B. The result is that the transfer price for 2020 will be high and the domestic expansion of RES in country B will be more efficient than expanding RES in country A even though the technology costs are lower here. The value of the generated electricity is simply higher in country B than in country A.

One consequence of the uncertainty regarding the future target is that renewable technologies with the shortest lifetime will be favoured as the total costs per generated unit in 2020 will be the least.

An EU policy for the future RES targets, which as a minimum establishes future targets at the level agreed for 2020, would reduce the uncertainty of post 2020 RES credits value. Such an announcement may facilitate cooperation just by reducing the uncertainty and contribute to reaching the 2020 RES targets at a lower aggregate cost.

The common Swedish-Norwegian certificate scheme effective from 2012 is one solution to reduce the cooperation barriers created by different support systems. The common system with an obligation for both countries post 2020 results in a price uncertainty for fulfilling the RES target that is similar for the two cooperating countries and not with opposite sign as in the case discussed above. Other countries have been addressing this option [7] in order to reduce their 2020 compliance costs. Despite a large number of common characteristics in Norway and Sweden, such as a common wholesale power market and a comparable geology for hydro reservoirs, it has required lengthy negotiations since 2005 before an agreement was reached. The 
main reason for this first failure was that cost attribution could not be agreed upon between the two involved countries. The producers of renewable certificates are approved in the home country (Sweden or Norway). Certificates will be assigned up to 15 years after initialization though only until 2035. It is up to each country to decide who should buy certificates - and which kind of consumption should pay for the certificates. The certificate system is designed to last from the period January first 2012 until December 31 2035, reaching the maximum obligation levels in 2019 and 2020 after which the renewable shares are set to decline gradually. Facing this initiative of a joint support scheme, other countries as the Netherlands [22] have investigated if an association to this joint scheme was possible and beneficial to them.

\section{Concluding remarks}

Renewable electricity potentials and costs vary considerably among EU countries. These variations in combination with differences in power market structure and price levels must be included when examining the benefit of cooperating on meeting the 2020 EU RES targets.

The potential benefits of cooperation on reaching the 2020 RES targets are of considerable size, but the barriers for realising these potential savings are of similar size. Table 1 sums up the characteristics and issues specifically involved for each type of cooperation mechanism. The conclusion is that the joint projects are the simplest in terms of need to change regulation and legislation and therefore can be implemented in a shorter time frame. This type of cooperation has its advantage for larger projects such as tendered off-shore wind farms, whereas the smaller projects would involve relatively more administrative costs in negotiating and designing individual contracts. In case of smaller projects, this could be possible if standardisation of contracts and conditions is possible.

The most important barriers are associated with the different objectives of renewable policy priorities of the countries. The large differences in existing support schemes, power markets and power sector regulation also form considerable barriers. One specific important barrier is the large uncertainty regarding the future RES targets. Financing RES expansion in another country

just to meet the RES targets for one single year in 2020 can be very costly as demonstrated in Table 2 .

The simplest solutions in terms of maintaining existing legislation and domestic support schemes, but adding new dimensions for support will be the easiest and fastest to implement. Here we suggest to look into larger projects for project based cooperation and the joint support schemes added on top of national support schemes for specific technologies or areas/regions.

Cooperation mechanisms involving countries with similar priorities and large differences in compliance costs seem the easiest to implement. In this case, even the harmonised single joint support scheme could be a solution to start moving towards, by defining compensation principles and methods and preparing the national markets for the change. 
Joint project cooperation where there are both benefits from difference in RES technology costs and benefits from expected difference in power market prices and physical market transfer will have the best chances for being implemented. However negotiating the transfer price for credits in 2020 is difficult especially since the country binding targets post 2020 are unknown and the value of future generated RES credits therefore very uncertain. This may lead to a sub-optimal preference for projects with a short lifetime. Announcing some direction for the future binding targets of EU would improve on this situation and reduce this barrier for cooperation.

\section{Acknowledgements}

This paper is partly based on research carried out as part of the RES4LESS project under the Intelligent Energy Europe program, Grant IEE/09/999/SI2.558312. A previous version was presented at the 12th Global Conference on Environmental Taxation, Madrid, in October 2011, and later published in the conference proceedings [23]. The authors would finally like to thank an anonymous referee for comments. 


\section{References}

[1] A. Tolon-Becerra, X. Lastra-Bravo, F. Bienvenido-Barcena, Proposal for territorial distribution of the EU 2020 political renewable energy goal, Renewable Energy 36 (2011) 20672077.

[2] J.C. Jansen, Do we need a common support scheme for renewables-sourced electricity in Europe? And if so, how could it be designed?, ECN-O--11-058 report, October 2011.

[3] Directive 2009/28/EC of the European Parliament and of the Council of 23 April 2009 on the promotion of the use of energy from renewable sources and amending and subsequently repealing Directives 2001/77/EC and 2003/30/EC. L 140/16.

[4] European Commission, COM (2013) 175 final: Renewable energy progress report, REPORT FROM THE COMMISSION TO THE EUROPEAN PARLIAMENT, THE COUNCIL, THE EUROPEAN ECONOMIC AND SOCIAL COMMITTEE AND THE COMMITTEE OF THE REGIONS.

[5] L. Kitzing, C. Mitchell, P.E. Morthorst, Renewable Energy Policies in Europe: Converging or Diverging?, Energy Policy 51 (2012) 192-201.

[6] S.T. Schröder, L. Kitzing, H. Klinge Jacobsen, L.L. Pade Hansen, Joint Support and Efficient Offshore Investment: Market and Transmission Connection Barriers and Solutions, Renewable Energy Law and Policy Review, 2 (2012) 112-120.

[7] C. Klessmann, P. Lamers, M. Ragwitz, G. Resch, Design options for cooperation mechanisms under the new European renewable energy directive, Energy Policy 38 (2010) 46794691.

[8] A. Türk, D. Steiner, D. Frieden, F. Prettenthaler, G. Resch, A. Müller, L. Liebmann, K. Steininger, M. Sommer, Asessing the role of cooperation mechanisms for achieving the Austrian 2020 renewable energy target (project ReFlex), Joanneum Research/Vienna University of Technology/University of Graz, Working Paper, Oct. 2012.

[9] M. Ragwitz, P.d. Río González, G. Resch, Assessing the advantages and drawbacks of government trading of guarantees of origin for renewable electricity in Europe, Energy Policy 37 (2009) 300-307.

[10] U. Lehr, J. Nitsch, M. Kratzat, C. Lutz, D. Edler, Renewable energy and employment in Germany, Energy Policy 36 (2008) 108-117.

[11] B.V. Mathiesen, H. Lund, K. Karlsson, 100\% Renewable energy systems, climate mitigation and economic growth, Applied Energy 88 (2011) 488-501.

[12] M.I. Blanco and G. Rodrigues, Direct employment in the wind energy sector: An EU study, Energy Policy 37 (2009) 2847-2857.

[13] B. Hillebrand, H.G. Buttermann, J.M. Behringer, M. Bleuel, The expansion of renewable energies and employment effects in Germany, Energy Policy 34 (2006) 3484-3494.

[14] N. Hanley and C. Nevin, Appaising renewable energy developments in the remote communities: the case of the North Assynt Estate, Scotland, Energy Policy 27 (1999) 527-547. 
[15] C. Klessmann, The evolution of flexibility mechanisms for achieving European renewable energy targets 2020- ex-ante evaluation of the principle mechanisms, Energy Policy 37 (2009) 4966-4979.

[16] L.L. Pade, H. Klinge Jacobsen, Barriers and Critical Success Factors for the Implementation of Cooperation Mechanisms., RES4Less Deliverable 3.1, 2012,

http://www.res4less.eu/files/deliverables/RES4LESS_D3\%201_Barriers\%20and\%20Critical\%20 Success $\% 20$ Factors $\% 20$ for $\% 20$ the $\% 20$ Implementation\%20of\%20Cooperation.pdf

[17] R. Haas, C. Panzer, G. Resch, M. Ragwitz, G. Reece, A. Held, A historical review of promotion strategies for electricity from renewable energy sources in EU countries, Renewable and Sustainable Energy Reviews 15 (2011) 1003-1034.

[18] S. Ropenus, H. Klinge Jacobsen, S.T. Schröder, Network Regulation and Support Schemes:

How Policy Interactions Affect the Integration of Distributed Generation, Renewable Energy 36 (2011) 1949-1956.

[19] S.T. Schröder, Interconnector capacity allocation in offshore grids with variable wind generation, Wind Energy 16, 2, (2013) 309-319.

[20] H. Klinge Jacobsen S.T. Schröder, Curtailment of renewable generation: Economic optimality and incentives, Energy Policy 49 (2012) 663-675.

[21] G. Resch, M. Gephart, S. Steinhilber, C. Klessmann, P. del Rio and M. Ragwitz COORDINATION OR HARMONISATION? FEASIBLE PATHWAYS FOR A EUROPEAN RES STRATEGY BEYOND 2020, Energy and Environment 24, No. 1 \& 2, (2013) 147-168 [22] J.C. Jansen, A. Uslu, P. Lako, What is the scope for the Dutch government to use the flexible mechanisms of the Renewables Directive cost-effectively? - A preliminary assessment, ECN-E--10-020 report, March 2010.

[23] H. Klinge Jacobsen, L.-L. Pade Hansen, S.T. Schröder, L. Kitzing, Joint Support Schemes for Renewable Generation and Barriers for Implementation, in: A. Yábar Sterling, P.M. Herrera Molina, J. Rodríguez Márquez, I. Bilbao Estrada, E. Eseverri Martínez (Eds.), Market instruments and sustainable economy, Instituto Universitario de Ciencias Ambientales/Instituto de Estudios Fiscales, Madrid, 2012, pp. 23-38. 